\title{
Homework: An Overload on Chinese School Children
}

\author{
Jianjun Zhang
}

Shandong University of Technology, China

\begin{abstract}
For a long time, the heavy burden of homework of primary and middle school students in China has been perplexing people in all walks of life especially the parents of children. This paper aims to analyze the influence of heavy homework burden on children's physical and mental health, academic development and relationship between school and home, and the causes of these effects. It is hoped that this paper can arouse the attention of primary and secondary school teachers who can take corresponding measures to reduce the burden of primary and secondary homework.
\end{abstract}

\section{Keywords- Primary and secondary school,} Schoolchildren, Homework, Physical and mental health.

\section{INTRODUCTION}

Homework, as an important part of students' schoolwork, has been a heavy burden on Chinese schoolchildren. This problem has already become very serious, which mainly demonstrates in terms of too much homework, lack of students' sleep and so on. A survey report shows that the average daily homework of primary and middle school students in China is 3 hours, which is twice the global average, with sleep less than 7 hours. For example, 15.2\% of Nanjing (2015) primary and middle school students do homework till late at night to 23 o'clock. This far exceeds the primary and secondary school students' sleep standards set by the National Ministry of Education and the level of the surrounding countries, and seriously damaged their physical and mental health and continuous development of education. I think, the reason that causes this problem has many aspects, among which examination-oriented education is the main one, that is, all the school teaching work revolves around the high school entrance examination and the university entrance examination, overemphasizes the students' examination results and neglects to implement the true quality education to students. However, teachers who are in the first line of teaching lacking full understanding of the role of homework, paying too much attention to students' test results and their own interests are also an important factor that cannot be ignored.

\section{THE INFLUENCE OF OVERLOAD OF HOMEWORK ON SCHOOLCHILDREN}

\subsection{Seriously impair the health of Schoolchildren}

Primary and middle school students are in the critical period of physical development, so appropriate sleep for physical health is particularly important. But many middle school students in China go to bed at 11 or 12 o'clock in the evening and get up at 5 o'clock in the morning with sleep time only about six hours. Scientific research has shown that staying up too late and getting insufficient sleep for a long time can not only cause vision loss and cervical or lumbar spine problems, but also cause students' thinking ability to decline, alertness and judgment impairment, immune dysfunction, imbalance, bad concentration and memory, and even cause sudden death.

Too much homework can also have a negative effect on students' psychological health. For example, to cope with teachers so as to escape the homework inspection, some students learned to lie, skimp, copy and conduct other 
bad behaviors; Some students even created reverse psychology toward teachers to complain about their teachers from the heart only to dislike their teachers and even their classes. As time passes, they will become tired of learning psychologically, and the interest in learning will disappear soon.

\subsection{Overdraft students' enthusiasmfor learning}

Learning is orig inally a happy thing, students should have a thirst for knowledge and curiosity to explore the mysterious world, and obtain happiness and satisfaction in the process of exploration. But in almost every night, they had to face piles of homework in the form of test papers; As a result, they often feel not pleasure and satisfaction, but boredom and helplessness. The heavy homework changes happiness into a kind of pain and suffering, and made some students lose their interest in pursuing learning and enthusiasm. Homework becomes undoubtedly the best fire extinguisher to put out students' curiosity for learning.

\subsection{Affect the normal school life of students}

Many students often fall asleep in class by the day because they stayed up too late in the last night for their homework. They cannot concentrate on listening to the teachers. Because of homework the normal classroom learning is affected greatly, it may be said an action to put the cart before the horse. What's more, some students feel sick the next morning because they went to bed too late at night, they have to ask for a leave to stay at home to rest or even go to see a doctor. They cannot go to school for the classroom learning, this is more than a loss.

2.4 Affect the normal relationship between school and home

The healthy growth of children is inseparable from family education and school education. In general, the family is responsible for the children's basic quality education, such as the training of children's basic life skills, civilized courtesy and honest quality, while the school is responsible for children's cultural knowledge, social norms, moral norms and values, of course, the imparting cultural knowledge is the main work of teachers. However, as homework is arranged more and more, many teachers seem to be unable to correct all of their homework, so some teachers begin to ask the parents to help them check and even correct the homework for children, as a result, their own work is transformed to the parents of the schoolchildren.

According to a report (2018) published by the China Artificial Intelligence Education Platform for Primary and Secondary Schools, more than 90 percent of parents have ever accompanied their children to do ho mework, nearly 80 percent of whom have been with their children every day, more than a third have lost their personal time altogether, and a quarter have even done homework assignments for their children. The home work burden on children evolved into one on children's parents, which inevitably causes parents to complain against school teachers, gives rise to many contradictions and finally an intense relationship between schooland home.

\section{CAUSES OF OVERLOAD OF HOMEWORK}

3.1 Deeply influenced by traditional ideas

Proper homework has a certain advantage. It can not only train the students' study consciousness and good learning habit, but also help the teachers to understand the classroom teaching effect and the degree to which the students grasp the knowledge point, so as to adjust the class room teaching method and the teaching focus in time. For a long time, the attitude of many primary and secondary school teachers toward homework is like this: " Do is better than not do, do more is better than do less." Because they always believe these sayings as "Practice makes perfect ", "To read 300 Tang poems fluently, even if you cannot write, you can chant at last". In fact, this is the result of traditional educational ideas. In the 1950s and 60s, former Soviet educator N.A.Kaiipob (1893-1978) believed that the purpose of homework was "to enable students to consolidate what they had learned and to improve their 
skills and techniques". Many primary and middle school teachers not only inherit and strengthen this theory, but also reduce the homework from "the organic part of teaching work" to "the extension of classroom teaching" or "the continuation of class". Affected by this concept, many teachers, while assigning the home work, inevitably cannot get rid of such problems as stereotyped and monotonous form, mechanical duplication, emphasizing quantity and slighting quality, valuing competition and neglecting cooperation, all of which bring students large amounts of boredom and restlessness. In his book The Homework Myth, American famous writer Alfie Cohn argues that the traditional ho me work "is useless and meaningless to study", "extra work that intelligent students despise and backward students refuse to do ". A lot of research at home and abroad shows that more practice can help some students to be good at correct response, but it will not help them to be good at thinking. In other words, practice often leads to habits, which are repetitive behaviors that require no thought rather than understanding, while the basic purpose of education is to train students' abstract thinking ability.

\subsection{Lack of communication between teachers}

At present, many primary and secondary schools in China are centralized at the departmental level, but there is a lack of proper communication in the arrangement of homework for schoolchildren. When assigning homework, for their own reasons, many teachers think their disciplines are more important than others, so they tend to assign more homework. The lack of coordination and communication between teachers often leads to the total amount of homework beyond the expectations of students, even their ability to bear, which is actually a selfish act under the examination-oriented system, a disrespect and irresponsibility to students. Therefore, we hope that the teachers should understand and communicate more with each other, take the overall situation into account, make overall arrangements so as to strictly control the total amount of homework and pay more attention to quality than quantity. Only in this way can the students' homework volume be reduced gradually.

\subsection{Lack of research on homework forms}

Due to the heavy teaching tasks and insufficient time, many teachers are unwilling to study and explore new forms of homework and individualization problems, and some still think that the traditional forms of homework are much better. In fact, homework is not "the more the better," but "the finest the better." This is a student-centered concept which requires teachers to spare time to do more research on the scientific design, and conduct more work from the content and form of the homework. For example, for primary students, teachers should arrange homework as much as possible to fit into the family, for which students will not feel home work activities and reading activities; For students of higher grades, more typical, targeted assignments should be arranged, instead of simple repetition, mechanical operation training without thinking. At the same time, the homework must be individualized, and accord with the students' physical and mental development characteristics; As for those students who often make mistakes in their homework, teachers should let them understand that making mistakes gives them an opportunity to learn from them. Teachers should concern more about the students with learning disabilities, and do more work on individual processing. Only in this way can it be conducive to the training of students' good homework habits, and achieve more with less. If teachers only want to keep the traditional homework layout so as to save their time and energy rather than hardship and troubles, the result can only be that the workload is transferred to students who have to bear a heavier and heavier burden. Frankly speaking, this is an irresponsible behavior.

3.4 Lack of adequate awareness and understanding of the influence of homework on children

Many primary and secondary school teachers pay too much attention to their students' academic achievements as well as their daily teaching affairs, ignore the harm that 
homework can bring to their students and pay insufficient attention to the issue reflected by the society. Some of them think that it is far from being the truth and even a little alarmist. They don't admit that there exists such a problem in their school or classes. Because they cannot face the reality directly, they are not able to calm down to do some investigation and research seriously, but to care little about it and go their own way, which cause the problem more seriously only to ultimately injury children and the future of the motherland.

\section{CONCLUSION}

There are many reasons for the excessive homework of students from primary and middle schools: Some are from the institutions; Some are from the education supervision of administrative departments; Some are from the one-sided pursuit of transition rate of schools. Of course, more are from teachers. Many teachers are excessively concerned about students' scores, so they are reluctant to take part in the study of the educational teaching theory to improve themselves; They are afraid of hardship and troubles and unwilling to work on the design of homework so as to change the traditional mode of homework; They are unwilling to face up to the real problem, ignoring the harm caused to students by too much homework. The results of these practices are not conducive to reducing the students' workload. Therefore, I think that primary and secondary school teachers should try to do the following things accordingly: First, they should try to study more, learn from and think about the relevant research at home and abroad; Second, they should make clear that the fundamental purpose of education is to train students' abstract thinking ability; Third, they should pay more attention to improving students' understanding; Fourth, they should strive to improve the quality of classroom teaching ; Last, they should pay more attention to the quality of homework than the quantity. Only in this way can they do more with less work, and really reduce students' workload of their own efforts.

\section{REFERENCES}

[1] Alfie Kohn. 2017. The Homework Myth (Chinese Version). Beijing: Education Science Press.

[2] Yuanyuan Yao. 2015. On primary and middle school in China having an average of 3 hours of homework with insufficient sleep per day. Nanjing: Jinling Evening.

[3] Shuo Zhang, Wenming Yang, Yuanyuan Chen. 2018. From reducing the burden of heavy schoolwork to solving the burden of extra-curricular. China News Network.

[4] Chengming Li. 2010. We should not obsess about the homework-Reflection on Reading "The Homework Myth". Jellyfish Web site.

[5] Shenglong Chang. 2010. The Role of Everlasting Dragon's Homework-Reflection on Reading Alfie Cohn's" The Homework Myth". Sina Blog.

[6] Yinhua Gu. 2013. Sets up English extracurricular work skillfully, trains the independent study ability. Exam and appraisal.

[7] Xiaolu Chen. 2015. Law Perspective on Overload of Middle and Primary School Students. People's Forum. 